\title{
Time Perception and Industrialization: Divergence and Convergence of Work Ethics in Chinese Enterprises in Africa
}

Tang Xiaoyang ${ }^{*}$ and Janet Eom ${ }^{\dagger}$

\begin{abstract}
As Chinese investors set up business operations in Africa, disagreements between Chinese and Africans regarding work attitudes have emerged. A prevailing view is that cultural differences cause tensions between groups with regards to the meaning of "hard work," "discipline" and "eating bitterness." However, we argue that conflicting perceptions of work ethics between Chinese and Africans are instead caused by evolving notions of time that accompany a transition from a pre-capitalist manner of production to that of industrial capitalism. First, we refute the assumption that culture determines work ethics. Second, we show that when a society industrializes, its notions of work ethics and time perception change; we then show how China's industrialization impacts its approaches to operations in Africa. Third, we use two case studies of Chinese investments in Tanzania and Ethiopia to illustrate how Chinese managers are changing African workers' attitudes through time discipline. Finally, we discuss the implications of a convergence of work ethics between Chinese and Africans.
\end{abstract}

Keywords: Chinese investment; African industrialization; work ethics; time discipline; role of culture

\section{"Hardworking" Chinese and "Lazy" Africans}

The number of Chinese investors in Africa has grown exponentially in recent years. According to the Chinese Ministry of Commerce (MOFCOM), 888 Chinese firms had registered to invest in Africa by 2010; that number had grown to 3,049 by 2015. ${ }^{1}$ As more Chinese firms have moved to Africa, their

* Department of International Relations, Tsinghua University. Email: tangxyang@tsinghua.edu.cn (corresponding author).

$\dagger$ China-Africa Research Initiative, Johns Hopkins School of Advanced International Studies. Email: janeteom@post.harvard.edu.

1 However, the actual number of Chinese businesses - in sectors ranging from mining and construction to manufacturing and food services - is likely to be higher, since many small and medium-sized investments are not required to register with MOFCOM. 
treatment of local workers has attracted the interest of researchers and policymakers.

There is scant reliable employment data on Chinese firms in Africa owing (but not limited) to rapid changes in newly established Chinese firms, deficiencies in labour registrations in China and Africa, and inconsistent employment statistics across African countries. However, studies show that Chinese firms often hire large numbers of African workers. Employment data collected by Deborah Brautigam and Xiaoyang Tang from six Chinese industrial zones across Egypt, Nigeria, Zambia, Mauritius and Ethiopia revealed the employment of 12,192 African workers, which accounted for approximately 85 per cent of the total workforce in those zones. ${ }^{2}$ In a separate study, Barry Sautman and Yan Hairong found that over 80 per cent of employees at 400 Chinese enterprises and projects in over 40 African countries were locally sourced. ${ }^{3}$

Although Chinese firms employ Africans, work-related tensions persist. Chinese employers have criticized their African employees for being "slow," "inefficient," "backward" or "lazy." For this study, we surveyed a total of 87 Chinese manufacturing firms across Ethiopia, Ghana, Tanzania and Nigeria, from 2012 to 2014. These firms reported the recruitment of a total of 15,052 African workers and 688 Chinese workers as of 2014. However, of the Chinese managers interviewed, 56 per cent held negative views towards African workers for "lacking discipline" and "not showing up on time." 4 For example, one Chinese manager at a glove-making factory in Addis Ababa accused his Ethiopian trainees of tardiness: "The workers don't relate the company's profit and costs to their own income. They should start working at 7:30 am, but most come in just at 7:30 am. After they greet each other and prepare for work, half an hour is lost. The company pays the workers for every minute, but they don't work every minute."5

Such views not only make Chinese employers unwilling to hire and promote more Africans but also lead to workplace conflicts. Chinese prejudice against Africans is widespread across countries and sectors. Marcus Power, Giles Mohan and May Tan-Mullins observed that Chinese labour was preferred over African labour for all but menial tasks such as waiting, cleaning and security, because as a Chinese trader in Ghana told them, "Our [Chinese] tempo is too fast for the local people." 6 Ching Kwan Lee interviewed a Chinese manager at

2 Brautigam and Tang 2014.

3 Sautman and Yan 2015.

4 The purpose of these surveys was to conduct scoping studies, or preliminary assessments, of all Chinese manufacturing investments in Africa. Ethiopia, Ghana, Tanzania and Nigeria were the countries where most Chinese manufacturing investments were concentrated (except for relatively industrialized South Africa), according to the 2014 MOFCOM database. The 87 firms represent the full extent of Chinese manufacturers we were able to reach. They cover different manufacturing sectors, including textiles, leather, footwear, plastics and construction materials. Questions on labour relations were asked in the survey. We also interviewed individual managers and employees at all of the firms surveyed.

5 Interview with Billy Yang, manager of Pittards Glove Factory, Addis Ababa, July 2012.

6 Power, Mohan and Tan-Mullins 2012, 174. 
the Sino-Tanzanian Urafiki Textile Mill who lamented his African workers' "backward" work ethics. ${ }^{7}$ Zambian workers at the Chinese-owned Collum Coal Mine complained that "If you are slow at your work, the Chinese beat you." A Chinese operator at the same mine retorted, "They [Zambian workers] have four or five days off every month because they need to go to church. You know, they are kind of lazy. They work like 10 to 15 days but want a full month's salary." 9

The prevailing view is that cultural differences cause these tensions. However, we argue that there is another cause: different manners of production. In particular, manners of production in industrial capitalist societies, characterized by a unique perception of time, create a sense of work ethics different from that of precapitalist societies. Over the past few decades, market-oriented reforms in China have promoted industrial capitalism and its corresponding work ethic. When Chinese investors arrive in Africa, this industrial work style comes into conflict with local, traditional work attitudes, as happened in China and other parts of the world previously. But gradually, a convergence between these different types of work ethics is emerging as industrial capitalism spreads.

This paper proceeds in four sections. First, we show that culture is likely not the primary and certainly not the only determinant of work ethics. Second, we demonstrate how as societies in Europe, China and Africa alike have transitioned to industrial capitalism, they have undergone similar changes in time perception, and consequently, work ethics. We show how Chinese firms' own industrialization at home impacts their management of time and work ethics in Africa. Third, we examine factories in Tanzania and Ethiopia where Chinese managers have influenced their African employees' work ethics through time discipline. Finally, we discuss the implications of a convergence of work ethics between Chinese and Africans.

\section{The Role of Culture, or Lack Thereof}

Is the difference in work ethics caused by cultural differences? This is a common explanation in the field. When Chinese investors established the Huajian Shoe Factory outside Addis Ababa in late 2011, Mulu Gebre was one of the first Ethiopian employees. But she quit six months later, citing cultural differences: "All [Chinese] supervisors like to shout. The Chinese are doing everything fast, but Ethiopian culture teaches people to act slowly." 10 Karsten Giese recorded what a Ghanaian at a Chinese-owned hotel outside Accra told him: "There are big cultural differences that make working for the Chinese difficult. The Chinese themselves are working around the clock. They are very hard-working

10 Interview with Mulu Gebre, former employee of Huajian Shoe Factory, Debre-zeit, July 2012. 
and it seems they never sleep." 11 In another study, Chinese traders thought "too much culture" in the Ghanaian community distracted local workers, who missed work to attend funerals or clan events. ${ }^{12}$ Although these cases are not representative of all Chinese investments in Africa, they show that workers and managers believe work ethics are somewhat culturally determined.

Various scholars support a culturalist explanation of Chinese work ethics. Melissa Wright argues that draconian disciplinary measures for controlling labour in China are influenced by Confucian cultural expectations. ${ }^{13}$ Tai Hung-Chao stresses that millennium-long Chinese cultural traditions have shaped the "Oriental model" of diligent and frugal Asian workers. ${ }^{14}$ Geert Hofstede and Michael Bond attribute East Asia's economic growth to regional cultural roots that emphasize hard work as a Confucian virtue. ${ }^{15}$ Herman Kahn identifies two aspects of Confucian ethics as important to modern development: "the creation of dedicated, motivated, responsible, and educated individuals" and "the enhanced sense of commitment, organizational identity, and loyalty to various institutions." 16 These studies argue that collectivist Confucian values emphasizing diligence, loyalty and education are largely responsible for creating a sense of discipline and industriousness that has supported China's economic take-off since the 1980s. ${ }^{17}$

However, as Susan Greenhalgh critiques, such scholarship simplistically "uses Orientalist cultural categories to understand Oriental economic outcomes."18 Before China entered its period of rapid growth in the 1980s, Chinese cultural traditions were often considered backward and disadvantageous for modernization. Chen Xi describes Chinese workers as being "lazy" during the early period of economic reform and attributes this characteristic to traditional perceptions of time in rural Chinese society, which contrasted sharply with modern perceptions of time in Western industrial society:

Even if [the Chinese] have working plans, they are easily distracted and interrupted by other things. This is demonstrated by the fact that people seldom make appointments in advance for social activities, do not keep strict time ... and are tolerant even when people do not keep appointments. In some offices, people may chat and work at the same time. When one thing is not finished, they can leave it for tomorrow. Although ancient people have mottos like "life is short" and "time is precious," these have never become part of common awareness. ${ }^{19}$

Likewise, in her study on Chinese female workers, Pun Ngai records the thoughts of Hong Kong managers who considered mainland Chinese workers to be too socialist and too rural for capitalist production: they were "uncivilized,"

11 Giese 2013, 143.

12 Power, Mohan and Tan-Mullins 2012, 174

13 Wright 2003.

14 Tai 1989.

15 Hofstede and Bond 1988.

16 Kahn 1979, 122.

17 Huang Kuang-Kuo also explored the connection between Confucian ideas and East Asian modernization. See Huang 1988.

18 Greenhalgh 1994, 749.

19 Chen 2007, 54-55. Authors' translation. 
undisciplined and left their work at will. ${ }^{20}$ Today, such comments sound similar to how Chinese managers describe African workers.

Hence, we question the validity of a purely culturalist explanation of work ethics. Furthermore, these historical narratives of Chinese "laziness" raise questions about why Chinese work ethics have changed so much and whether there is in fact a distinctly "Chinese" work ethic. We observe that Chinese society's evolving work ethics can be characterized by changing perceptions of time. Furthermore, we find that such changes have occurred in the context of industrial development. Given the changes in China's industrialization, we hypothesize that the newly arriving Chinese factories will exert an influence on their African employees' work ethics and time perception, and we present evidence from the field that supports this view.

\section{Industrial Capitalism and the Transformation of the Perception of Time}

Our contradictory observations of Chinese as both "hardworking" and "lazy" raise an additional question: what are the criteria for defining or measuring "hard work" and "laziness?" While Chinese workers from rural areas were considered undisciplined and uncompetitive by Western and Hong Kong standards of efficiency in the modern workplace, they were also described as working from dawn to dusk without rest and painstakingly taking care of crops. ${ }^{21}$ Similarly, observers have described tireless African bus drivers and street vendors who work around the clock in cities across the African continent. Former Chinese ambassador Cheng Tao 程涛 writes, "In fact, Africans are very capable. African women are especially diligent and capable. They work in the field and take care of the household. We often see them lift heavy stuff on their head, a large bag of crops or a large bunch of wood, even a large container of water." ${ }^{22}$ Hence, the same group of people can be viewed as hardworking or lazy, according to different standards. In this paper, we refer to criticism of "lazy" Chinese and Africans in the context of industrial discipline. Heavy domestic work or agricultural labour using antiquated farming methods does not necessarily count as desirable work ethics in the factory workplace of modern industrial capitalism, as we show below.

Labour historians have argued that industrial capitalism requires a particular set of work ethics that are characterized by a close relationship between time and monetary value. As Benjamin Franklin famously wrote in 1748, "Time is money." ${ }^{23}$ E.P. Thompson distinguished between leisurely task time, where a sense of time depends on simply finishing a task as needed, "so effort varied seasonally ... [and] work rhythms were integrated into patterns of social life," and 
rigid clock time, where the rise of wage labour and strict discipline in the factory leads to the capitalist wanting to "get his precise due" by buying his labourer's time. ${ }^{24}$ Task time corresponded to pre-industrial Europe; clock time only arrived after the rise of industrial capitalism. Workers in the West used to follow a flexible working schedule, without connecting hours worked to money earned. ${ }^{25}$ However, a new time-discipline was gradually imposed on European workers in the 18th and 19th centuries through "the division of labour; the supervision of labour; fines; bells and clocks; money incentives; preachings and schoolings; the suppression of fairs and sports." 26 Thompson wrote that for those "accustomed to labour timed by the clock," the traditional task-based ethics to labour appears "wasteful and lacking in urgency." 27

Similarly, Moishe Postone traced the origins of working hours to the clothmaking industry in Western Europe in the 14th century. Unlike most medieval "industries" of boutique workshops producing for the local market, the clothmaking industry was the first to engage in large-scale production for export. Hiring thousands of wage labourers, the merchants could no longer rely on "natural time" marked by sunrise or sunset. Towns began using work bells to announce the beginning and end of the workday and meal intervals. Disciplining and coordinating workers through standardized hours were considered effective measures to improve productivity. The merchants, whose profits came from the difference between the value of the cloth produced and the wages paid, were keen to increase the productivity of workers in a given time. ${ }^{28}$ In contrast, the notion of productivity was apparently unknown in ancient China, where production was not monetized on a large scale and the number of wage earners was limited. ${ }^{29}$

In fact, until half a century ago, Chinese rural society maintained a traditional notion of time perception. In the late 19th century, Arthur Smith described how the Chinese worked long hours but disregarded efficiency: "They are perpetually stopping to drink tea. They make long journeys to a distant lime-pit carrying a few quarts of liquid mud in a cloth bag, when by using a wheelbarrow one man could do the work of three; but this result is by no means the one aimed at. If there is a slight rain all work is suspended. There is generally abundant motion with but little progress, so that it is often difficult to perceive what it is which represents the day's 'labour' of a gang of men." ${ }^{30}$ In 1955, Lien-Sheng Yang wrote, "Modern Westerners sometimes criticize the Chinese for their lack of a sense of time in their daily affairs. One must remember that China

30 Smith 1894, 44. 
was an agricultural state in a pre-machine age where there was little need to be particular with time to the minute or second." 31

The Chinese notion of work ethics started to change as capitalism impacted the country. Wen-hsin Yeh noted how the landmark Custom House clock in Shanghai introduced modern, urban time discipline to dominate the practices of the emerging urban capitalists, merchants, and white collar and industrial workers. As a pioneer, Bank of China used a stringent schedule of work, vocational study and communal life to train its employees, in a largely self-contained environment, not only to become accustomed to the concept of uniform time but also to develop a work ethic closely related to time discipline. ${ }^{32}$ This model evolved to become the work unit (danwei 单位) in the socialist era, which continued training workers by regulating their work and life according to standardized clock time. However, the Chinese Communist Party despised the maxim, "Time is money," as representing capitalist values, and it cut out the links between time and monetary value. ${ }^{33}$ Consequently, the concept of industrial work ethics became distorted. Political campaigns occasionally promoted time discipline and production efficiency to boost industrialization. Yet, as an increase in profit was no longer the goal of production, the efforts to improve punctuality and efficiency depended on political instructions and were thus sporadic and inconsistent. Efficiency-oriented production was just one of the work manners which could coexist side-by-side with traditional lifestyles and egalitarian (daguofan 大锅饭) communism.

By comparison, efficiency-oriented production is the one work manner of industrial capitalism, for profit-seeking enterprises target nothing but productivity growth. In order to achieve more profit and survive in a competitive landscape, every producer under capitalism has to constantly improve efficiency and keep up with a stringent time schedule. Therefore, it was not until the beginning of market reforms that the industrial notion of time perception became significant and rapidly spread throughout the whole of Chinese society. When China set up its first special economic zone in Shenzhen in 1980 to experiment with a market economy, a large billboard was erected at the entrance to the zone bearing the slogan, "Time is money, efficiency is life." This served as a symbolic event in bringing back a capitalist drive. A national debate unfolded. The slogan drew criticism for "restoring capitalism." It was only after leaders like Deng Xiaoping 邓小平 showed their approval of the slogan that Chinese society came to widely accept the connections between time, money and efficiency. ${ }^{34}$

The changed perceptions of time and economic value were experienced concretely by numerous Chinese factory managers and workers. In a study of Liton (China) Electronics Limited in Shenzhen in the early 1990s, Ching Kwan 
Lee describes a new class of workers (dagongzai 打工仔) as “workers laboring for the bosses" in a system of both "modernity and prosperity" and "ruthless exploitation." 35 One worker recounted, "We Chaozhou girls have a tradition of doing embroidery work at home ... ten to fifteen girls sitting together, joking while working ... when you work you can arrange your time freely, but when you dagong, there are rules from your boss." 36 Another woman felt she was "kicked around like a football," moved from one position to another for greater efficiency. ${ }^{37}$ Likewise, in Pun Ngai's study, Hong Kong managers positioned Chinese workers in the assembly line to impose discipline and encourage efficiency, making the "socialist and rural" bodies work for capitalist production. ${ }^{38}$

We observe that most opinions of the different work ethics exhibited by Chinese and Africans also refer to "hard work" in terms of efficiency, speed and long hours. A local employee at Tooku Inc., a Chinese-owned garment factory in Dar es Salaam, described the Chinese preference for working fast: "The Chinese really work hard, and they expect us to work hard as well. At times, they really push you. They say Tanzanians are slow, especially when we receive big orders and the workload is high."39 Meanwhile, Adeyemo Thompson, a Nigerian deputy managing director of the Sino-Nigerian joint venture Lekki Free Trade Zone (LFTZ), considered working overtime as an example of Chinese-style hard work: "Nigerians are learning to work harder by following their Chinese colleagues and staying in the office every weekend." 40 Furthermore, "discipline" is related to punctuality. Workers at the East Star Shoe Factory in Dar es Salaam reported that: "The Chinese are very much on time, and they even arrive a bit earlier to start work." 41

Judgement of work performance in modern industries, no matter whether in Europe, China or Africa, universally highlights the importance of rigid discipline with respect to time. Modern perceptions of uniformly divided hours, punctuality, time value and productivity developed out of capitalist economies and large-scale industries. As industrial capitalism spread, both Western and Chinese societies gradually adopted a corresponding view that "time is money." Although teachings on "hard work" and "discipline" existed in ancient China, they held significantly different meanings from their association with Chinese work ethics today under industrial capitalism. Working overtime in the evenings or on weekends, emphasizing efficiency and productivity of time and adhering to punctuality are behaviours based on Chinese society's evolved

35 Lee 1998, 110-15.

36 Ibid., 114-15.

37 Ibid., 115.

38 Pun 2005, 79-81.

39 Interview with a Tanzanian worker in quality control department, Urafiki Textile Mill, Dar es Salaam, March 2015.

40 Interview with Adeyemo Thompson, deputy managing director, Lekki Free Trade Zone, June 2010.

41 Interviews with workers at Eaststar Shoe Factory, Dar es Salaam, March 2015. 
notions of time rather than on any static, culturally rooted devotion to work that characterizes Chinese workers.

African societies have also experienced changes in working styles with modern shifts in time perception. Keletso Atkins describes the influence of churches, municipalities and factories in urban South Africa in detaching African workers from old traditions and integrating them instead into new rhythms of the industrial workplace. ${ }^{42}$ Frederick Cooper argues that a British colonial administration that decasualized labour transformed the meaning of time for local dock workers by promoting adaptation to "the work rhythms of industrial capitalism: to the idea that work should be steady and regular and carefully controlled." 43 Bill Freund noticed that work patterns in different African urban areas diverged depending on their adaptation to modern industrial society; for example, miners in the Zambian copper belt became much more disciplined and professionalized than dwellers in Addis Ababa because of booming mineral development. ${ }^{44}$ Post-independence industrialization efforts have further led to a relatively strong working class in some countries, but the continent is still largely a rural-based economy. ${ }^{45}$ In 2015, 62 per cent of the population of Sub-Saharan Africa lived in rural areas, in contrast to 44 per cent of the population of China. ${ }^{46}$ Employment in industry made up 46.9 per cent of total employment in China in 2011, but only 14.4 per cent in Ghana, 9.5 per cent in Zambia, 8.5 per cent in Nigeria, 7.4 per cent in Ethiopia and 6.4 per cent in Tanzania around the same time. ${ }^{47}$ Most African countries lag behind China in industrial development and are not fully adapted to the time perception of industrial capitalism. ${ }^{48}$ Therefore, diverging judgements on time perception between Chinese and Africans lead to conflicts regarding work rhythms in daily operations. European capitalists who previously did not succeed in widely imposing modern clock discipline on African labour labelled Africans as "lazy." 49 Likewise, a new South-South divergence of time perception today creates the myth of "hardworking" Chinese and "lazy" Africans.

42 Atkins 1988, 237-243.

43 Cooper 1992, 209.

44 Freund 2007, 82-92.

45 Cox, Hemson and Todes 2004; Cooper 1983.

46 For rural population as a percentage of total population, see http://data.worldbank.org/indicator/SP RUR.TOTL.ZS. South Africa is a notable exception (only $35 \%$ of its population lived in rural areas in 2015).

47 For employment in industry as a percentage of total employment, see http:/data.worldbank.org/ indicator/SL.IND.EMPL.ZS. The industry sector consists of "mining and quarrying, manufacturing, construction, and public utilities." The statistics for each country vary by year: Ghana (2013), Zambia (2012), Nigeria (2007), Ethiopia (2013) and Tanzania (2014). The percentage of employment in industry in Southern Africa is higher than in other parts of Sub-Saharan Africa: $23.5 \%$ for South Africa in 2014 and $17.5 \%$ for Botswana in 2010.

48 Notably, African migrants in Europe were considered to work harder and more efficiently than Africans at home. See Haas 2008. This supports the notion that the societal context of developed industrial countries was a factor in inducing Africans to work according to the requirements of modern industries. It is not African culture but the lack of industry that has hindered Africans to work efficiently.

49 Cooper 1995, 235. 
Increasingly, Chinese firms in Africa are trying to solve the problem of diverging work ethics and transform local workers' time perception to match the requirements of industrial capitalism. However, these firms' approaches are different from those of other foreign powers in Africa and China. On the one hand, individual Chinese investors have neither a government's administrative capacity nor the help of churches or other social institutions; instead, they must rely on the power of factory management. On the other hand, even though the time discipline of industrial capitalism applies a universal clock time, manners of adaptation vary across different social and cultural contexts. The interaction between Chinese managers and African workers must involve cross-cultural communication and convergence. While culturalist views cannot fully explain the transformation of work ethics, it is short-sighted to exclude culture completely. Fredrick Cooper once criticized labour historians for merely emphasizing "what the workplace brought to African workers rather than the other way around." 50 In other words, local workers have agency. Therefore, we argue that Chinese and Africans are working together to overcome the divergence in work ethics and create a modern work force in Africa.

In the following section, we use two case studies to illustrate how Chinese managers are trying to change African work ethics and time perception. Both cases are of Chinese investment in manufacturing, a sector that emphasizes disciplining labour to clock time. As Thompson explains, while in other industries, precapitalist and capitalist work ethics coexisted side by side, manufacturing factories like textile mills were the first to adopt a strict working time schedule. ${ }^{51} \mathrm{In}$ addition, more Chinese firms are shifting their manufacturing bases abroad in recent years. ${ }^{52}$

Out of the 87 manufacturing projects surveyed in four African countries, we selected these two examples for several reasons. First, both firms employ a considerable number of workers. Only eight surveyed Chinese manufacturers reported more than 850 local workers. We believe that the effects of time discipline and coordination can be seen more clearly in factories with a critical mass of employees. Second, the two chosen cases represent two different trajectories. One factory was a Chinese aid project in the socialist era and has now been turned into a market-oriented joint venture in Tanzania, while the other factory is a new private investment in Ethiopia. Different countries and backgrounds illustrate different patterns of interactions between traditional environments and industrial capitalism, but they are comparable owing to their common pursuit of time value and discipline. Third, both projects are considered to be "flagship" cases in the China-Africa relationship by government, media and researchers, with studies already conducted at both factories. ${ }^{53}$ Analysis of these projects'

53 See Brautigam 2009, 197-201; Lin and Wang 2016, 165-66. 
labour management provides lessons for tackling the challenges, and understanding the impacts of, a new trend of African industrialization for a broad range of readers. We chose Tanzania and Ethiopia also because their current industrialization levels, like most Sub-Saharan African countries, are relatively low and the transformation process is identified more clearly. In addition to an overall survey, the researchers have visited both factories several times since 2009. In each factory, three to four separate day-long, on-site observations were conducted. Both Chinese and African managers and employees were interviewed. Except for top management interviewees, the authors selected Chinese and African workers randomly in the workshop for conversation.

\section{Case Studies on Converging Work Ethics}

Our analysis is based on phenomenological interpretations of dynamic daily practices in two factories. Real life experiences and interactions in the workplace never follow fixed rules, especially in a diverse intercultural context, even when modern factories strive to standardize them. Therefore, we choose not to measure the transition of work ethics with a standardized dataset or quantitative models; instead, we depict changes in individual mindsets by presenting cases from our field research. These cases cover various aspects of temporal perceptions in different places. Weaving them together, we do not aim to demonstrate how much Chinese employers have effectively changed African work ethics, as it is extremely difficult, if not impossible, to measure such changes. Instead, we have a more modest goal: to show that Chinese investments have indeed been changing the time perception of local workers and converging previously divergent work ethics.

The first case is Urafiki Textile Mill in Dar es Salaam, which was opened as a Chinese aid project in 1968 and converted into a Sino-Tanzanian joint venture in 1997; the Chinese partner is a state-owned company, Changzhou Textile Group. The second case is Huajian Shoe Factory outside Addis Ababa, a Chinese private investment set up in 2011. The Urafiki case illustrates changing modes of Chinese engagement with African workers and labour unions, whereas the Huajian case discloses strategies of Chinese private businesses on the factory floor. Both factories are labour intensive. The Urafiki mill used to employ almost 4,000 Tanzanians in the 1990s, but only 1,900 workers were kept on when the joint venture was formed. ${ }^{54}$ Owing to the mill's poor economic performance, the number of employees has continued to decrease: in August 2014, the total number of employees was only 860 Tanzanians and 17 Chinese. ${ }^{55}$ In contrast, the Huajian factory has experienced a rapid expansion. In July 2012, the factory had hired 1,000 Ethiopian and 100 Chinese workers; by January 2015, these numbers had swelled to 3,400 Ethiopians and 120 Chinese. ${ }^{56}$

54 Interview with Wu Bin, general manager, Urafiki Textile Mill, Dar es Salaam August 2014.

55 Ibid.

56 Authors' fieldwork, July 2012 and January 2015, Addis Ababa. 


\section{Urafiki Textile Mill}

The Urafiki Textile Mill faced labour inefficiency issues after the formation of the joint venture, causing tensions between Chinese and Tanzanians. Chinese managers complained of the Tanzanian workers' "obsolete ideas and low productivity." ${ }^{57}$ When workers took sick leave, managers could not verify whether they were truly sick or not. ${ }^{58}$ One day, the general manager, Wu Bin 吴涁, expressed anger over the suspension of production: six of the ten workers assigned to move a stock of materials had gone on sick leave, causing chaos. ${ }^{59}$ Meanwhile, workers were protected by a strong labour union that asked for higher wages and more welfare but resisted overtime. These workers had developed a certain sense of industrial clock time from the socialist era, for they were clearly aware of their work schedule. Yet, they did not link time discipline with economic efficiency, and this therefore sparked conflict with the Chinese managers. The management tried to cut down on permanent employees and casualize jobs. However, the effects were not as intended, and production decreased. ${ }^{60}$

In 2013, to improve worker productivity and respond to demands for a salary rise, $\mathrm{Wu}$ introduced a new incentive system based on "a combination of the 'overall' and the 'individual.". ${ }^{11}$ On the one hand, he gave salary bonuses and extra food to all employees during local holidays and festivals; such egalitarian methods were commonplace in China's socialist past. This is what Wu meant by the "overall." On the other hand, he attached more importance to giving bonuses and overtime pay to the "best workers," that is, those who produced the most in a given period of time. Workers in the weaving department could receive a bonus of 30,000 Tanzanian shillings (US\$20) if they reached a preset monthly target. For every additional metre of cloth weaved, another 20 shillings was offered. Overtime was paid as well, rewarding those who worked long hours. The most productive workers could earn as much as 250,000 shillings per month, whereas the fixed income for a worker without any bonus was usually about 100,000 shillings. ${ }^{62}$ This is what $\mathrm{Wu}$ meant by the "individual."

Many other Chinese firms introduced similar measures to reward productivity, but the results were not always satisfactory. Some enterprises reported that local workers were not willing to adopt the piece-rate system, the practice of paying according to output, because they were not skilled enough to produce large quantities and afraid they would make less income than on the default system. ${ }^{63} \mathrm{~A}$ Chinese manager in the Tooku Garment Factory located near the Urafiki Textile Mill reported that local workers used to return their bonuses because

57 Interview with Huang Lilan, (former) general manager, Urafiki Textile Mill, Dar es Salaam August 2009.

58 Ibid., and interview with Wu Bin, Urafiki Textile Mill, Dar es Salaam, September 2012.

59 Interview, Wu Bin, August 2014.

60 Lee 2009.

61 Interview, Wu Bin, August 2014.

62 Ibid.

63 Interview with Sun Linhua, director, Best Hubo Garment Company, Yangon, Myanmar, January 2016. 
they felt uncomfortable being singled out among peers. ${ }^{64}$ Labour unions in Tanzania also tend to resist a piece-rate wage system, viewing it as threatening to the workers' guarantee of income.

However, the bonus system in the Urafiki Textile Mill worked owing to three conditions. First, Wu noticed that the workers' fixed salary of 100,000 shillings per month, slightly above the minimum wage, was barely sufficient to support local workers and their families in Dar es Salaam. Therefore, workers were eager to earn additional income. In Wu's words, “The marginal effect of the 10,000 shilling bonus and overtime pay on top of the 100,000 shilling fixed salary is significant." 65 Second, he calculated the bonuses not just according to the output of the individual worker, but rather to the output of a group of workers. Workers were divided into teams under local supervisors; supervisors' bonuses were calculated on the basis of the average bonuses of their team members. Supervisors were therefore motivated to encourage the entire team to work more efficiently for longer hours. As a group, workers were more likely to be productive. Third, $\mathrm{Wu}$ ensured that all workers understood the firm's target by breaking it down into concrete pieces. Urafiki needed to produce at least 8 million metres of fabric per year to break even, but the factory usually could only produce 5-6 million metres. In order to make this target less daunting, $\mathrm{Wu}$ divided it into smaller targets for each group. In the last month, supervisors monitored their group's target each day, checking whether members had finished their daily targets before going home; if they had not, the whole group voluntarily worked overtime. As a result, the mill ended up producing 8.08 million metres of fabric that year. ${ }^{66} \mathrm{Wu}$ had created a factory culture in which raising productivity was a collective experience, and where workers were experiencing a direct connection between the hours they worked and the money they and the firm earned.

Soon, $\mathrm{Wu}$ noticed changes in the perceptions of the Tanzania Union of Industrial and Commercial Workers (TUICO). In the past, TUICO directly requested an increase in wages without any connection to the workers' production. But, in its 2014 May Day speech, the union requested the factories' management "to increase the workload so that the pay increases." On behalf of the workers, the union also stated: "We need to increase production this year. We are ready to work ... Planned production targets must be known to workers and the TUICO branch should be informed about these targets so that it can cooperate fully in the reaching of the targets." $67 \mathrm{Wu}$ was delighted with these requests: "They [the Tanzanian workers] have realized that they should make money through more work, and not simply demand a rise."68 The union

64 Interview, Hu Xianjun, manager Tooku Garment Factory, Dar es Salaam, August 2014.

65 Interview, $\mathrm{Wu}$ Bin, August 2014.

66 Ibid.

67 May-Day speech given by workers' representatives, Tanzania-China Friendship Textile Company, Dar es Salaam, 24 June 2014 (written version).

68 Interview, Wu Bin, July 2014. 
appeared to have revised its view of the relationship between time and money. Now, workers who wanted to earn more income thought of improving production efficiency and increasing their overtime.

A Tanzanian supervisor who has worked at Urafiki since 1968 described his impression of the changing management style of the Chinese: "Previously, the Chinese mainly paid attention to production itself, but currently they think more about business. They focus their attention on how to save time and how to reduce loss. Previously, they would teach Tanzanians again and again if Tanzanians could not grasp the skill within a short time. But now they would give a worker one week to learn a skill, and if he cannot get it, it's over." ${ }^{69}$ His observation revealed that he understood the essential characteristic of the new Chinese work ethics as not simply focusing on industrial production but on a close link between time and value.

\section{Huajian Shoe Factory}

The requirements of time discipline and efficiency are stricter in the Huajian Shoe Factory, which produces for international brands such as Guess, Tommy Hilfiger, and so on. The firm, which employs over 25,000 Chinese workers at home and bears the brunt of rising wages in China, is eager to relocate parts of its production capacity to Ethiopia. Thus, the case of the Huajian Shoe Factory more vividly shows a possible transition from "Made in China" to "Made in Africa."

First, the factory prioritizes punctuality. Inside the workshop is a large banner in Amharic, English and Chinese that reads: "Late arrival is delay, early arrival is waste, punctuality is integrity." Managers encourage punctuality with rewards and discourage tardiness with punishments. Workers who arrive on time every day for a month receive a bonus on top of their regular salary. If they are late once, they lose their entire bonus for the month. The factory also provides shuttle buses for the workers to commute between two nearby towns and the factory. This is not merely beneficial for the workers but also important for the factory. A factory manager described how the shuttle buses effectively help workers to arrive on time: "Otherwise, they would arrive scattered, some may come at 10 o'clock [in the morning]." 70 One researcher observed that the workers all assumed their proper places when the clock approached $8 \mathrm{am}$. A supervisor stood in front of every production line, making final inspections before work began. With the shrill blow of a whistle, the entire factory floor erupted simultaneously into operation.

The firm employs military-like drills for newly recruited workers, who undergo a week of physical training before starting work on the factory floor. One

69 Interview with Tanzanian workshop supervisor, Urafiki Textile Mill, Dar es Salaam, March 2015.

70 Interview with Chen Jixiang, factory production manager, Huajian Shoe Factory, Addis Ababa, July 2017. 
"formation drill" that workers participate in everyday consists of standing for long hours in the sun and going through coordinated exercises as a group, "turning left," "turning right" and "lining up in good order." The exercises, which simulate synchronized movements in the factory, are meant to impose discipline. New recruits who are not able to finish the training have to leave. The factory's general manager, Helen Hai, appeared satisfied with these methods of changing workers' attitudes: "Through militaristic training ... their [the local employees'] morals and appearances become very different from those of the people who are still waiting for jobs outside the factory gate. It [the training] is harsh, but it's good for them." 71

To improve efficiency, Huajian uses a bonus scheme, and like Urafiki, the bonus is calculated based on group performance. However, at Huajian, not only do teams that achieve their targets get bonuses but teams that produce the most output get additional rewards. Each team is made up of 20-30 Ethiopian workers and led by a Chinese supervisor, and competes to produce the most output as recorded by factory management. Each week, a winning team is selected. On a field visit, one of the researchers observed this in action. Workers were set up into parallel teams that made the same items. A blackboard recorded each team's output every hour. After a week, the factory manager announced the winner of this competition with a reward of a bonus and workplace honours. In total, three teams were selected as winners every week. The first team received 1,000 birr (approximately US\$50), with each individual on the team receiving about 50 birr. The second and third placed teams received less. Factory managers hung red banners over the assembly lines of winning teams to signify their success.

One morning, a team supervisor, Zhou Fei 周非, checked the tables of hourly outputs of all the teams. When he found his team was slowing down, he urged each worker to speed up. Before lunch, he summoned his team for a briefing on their performance. His team had won the competition the week before, and Zhou praised them for making good shoes and earning money. In the afternoon, he continued urging his team on, giving shoulder massages to several members to encourage them to work harder. Meanwhile, a supervisor of another team complained that his team could not win because the local workers were not interested in the competition. ${ }^{72}$ In general, however, a competitive environment turned out to be an effective approach to increasing production efficiency. Local shoemakers were impressed by the immense scale of production at Huajian. An Ethiopian factory manager recalled, "When I visited Huajian, I saw their massive operation, I was shocked. It was an army of people. Everybody was chikchikking (sewing and working), that's crazy! Ethiopians were not used to that. We could not do that. It was the first time that we saw this." 73 The emphasis on speed

71 Interview with Helen Hai, Huajian Shoe Factory, Addis Ababa, July 2012.

72 Interviews with Zhou Fei and Wu Runlu, Huajian Shoe Factory, Addis Ababa, July 2012.

73 Interview with Girma Ayalew, deputy manager, Fontanina, Addis Ababa, February 2015. 
has reached the point where the factory's boss, Zhang Huarong 张华荣, has encouraged local workers to do more, even if they make mistakes, because he does "not like workers who make fewer mistakes by doing less." ${ }^{74} \mathrm{He}$ argued that efficient workers are those who finish their tasks on time.

\section{Conclusion}

Overall, we find the culturalist explanation of Chinese and African work ethics is ahistorical. Rather, work culture in China changed dramatically with industrialization. Thompson and Postone revealed that the work ethics of industrial capitalism, characterized by a rigid clock system, a clear division of uniform time, and close connections between time and money, developed out of modern factories: a capitalist practice of employing large numbers of workers and demanding continuous growth of profit led to societal organization centred on standardized time and productivity. We argue that the positive valuation of working practices based on this mode of time perception is a result of the global spread of industrial capitalism. Many scholars observe the connection between time valuation and work ethics accompanying industrialization in the Middle East, Latin America, Russia and India. ${ }^{75}$ As Edwin Cohn writes, "Time commitments in the Middle East or in Latin America are often treated somewhat casually by European standards; new industrial workers only gradually become accustomed to regular hours, regular attendance, and a regular pace of work." 76

As industrialization spreads, corresponding production activities and time perception become dominant, replacing traditional work practices and modes of social life. However, the transition from traditional customs to modern capitalism is never the same. As Thompson writes, "There is no such thing as economic growth which is not, at the same time, growth or change of a culture; and the growth of social consciousness, like the growth of a poet's mind, can never ... be planned." 77 The adaptation of standardized production into a society is an interactive process between incoming industrialization and existing traditions in the country. Although modern factories appear uniform and standardized, they reflect local history and culture. Modern European, American and East Asian societies agree upon the merits of punctuality, efficiency and accumulation, but still differ from each other in terms of degree of discipline, lifestyle and visions of the future. ${ }^{78}$

The divergence and convergence of work ethics between Chinese and Africans today can be viewed as a new episode in the clash between "modern" and "traditional" societies. This latest tension is similar to previous ones with the more industrialized society, which attaches normative values to perceptions and

74 Interviews with Diro, Fasel, Esrael, Ethiopian workshop supervisors, Huajian Shoe Factory, July 2017.

75 Thompson 1967, 93.

76 Cohn 1964, 105-06.

77 Thompson 1967, 97.

78 Hall 1959, 25-35. 
behaviour related to rigid clock time, viewing the culture of the less industrialized society as backward. ${ }^{79}$ Yet, this new episode is also unique. Since most Chinese have adopted modern work ethics only in recent decades, it is possible that they have not yet developed a deep-rooted sense of superiority or established clearly systematic practices of discrimination. Chinese views of Africans, like African views of Chinese, are based on scattered observations mixed with prejudice. ${ }^{80}$ The interaction between Chinese and Africans in the workplace may help to reduce prejudices on both sides, as time perceptions and work ethics gradually converge through cooperation and mutual adaptation. We do not intend to generalize and speak for all "Chinese" and "Africans," and we emphasize our observations are based on specific cases which vary across time and space.

Furthermore, we demonstrate that dynamic changes to work ethics are taking place in Chinese factories in Africa in a mutually interactive manner. Chinese managers often borrow their experiences of training workers back home (for example, military-like physical training or team competitions) to influence their African workers' behaviour. But there are also signs that modifications are being managed to fit the local cultural context (for example, promoting piecerate wages by group). African workers do not simply resist or accept Chinese management; rather, they respond to new production practices. Without state administrative power, Chinese managers can only influence local workers incrementally through daily operations. This is not necessarily a negative development, as it facilitates more communication and reduces the risk of simply imposing industrial discipline on local traditions. We believe such concrete changes are helping to develop a qualified African work force in the manufacturing sector and can eliminate the perception of "lazy" Africans in the Chinese context. New forms of work ethics will gradually emerge in workshops in Africa through joint efforts between foreign investors and local workers.

Even as Chinese managers deliberately explore optimal methods for working with Africans, the stand-alone arrival of numerous Chinese firms and their employment of tens of thousands of Africans seem to have already facilitated the emergence of modern work ethics. Even when local workers are not yet fully integrated into factory operations, they become increasingly familiar with the concrete requirements of a new factory in the context of modern industry. As a Tanzanian worker reported:

The most important reason [for the lack of discipline] is that Tanzanians do not have relevant knowledge. We know which rules and procedures to follow at work only after we see the factory and machines. This knowledge was not given to us when we were born, but can only be learned later. For example, after I see the machines and the professional work done by Chinese in the shoe factory, I hope to be able to work like the Chinese. But without the factory and the machines, how can I know which rules I should follow? We cannot understand these things until we get jobs, such as I should go to work at what time in the morning, I should work how long every day and how much I can earn monthly. These are rules at work. Therefore 
Tanzanians do not intentionally disobey work disciplines. They do not follow the rules because they do not have jobs. ${ }^{81}$

Similarly, Sun Linhua 孙林华, a Chinese manager who has worked in the garment sector in Southern Africa for a decade, believes that skills improvement and discipline are a matter of time: "The workers will gradually learn the details of work after several years, as long as they are working in the factories. This is the case in China, South-East Asia and Africa." 82

If this is true, the key to nurturing modern work ethics in Africa is the employment of large numbers of Africans in factories. This seems paradoxical: an existing lack of skills and work ethics hinders the employment of local workers in the first place, and so the local labour force has limited opportunities to improve these skills and work ethics, in the factory or elsewhere. Nonetheless, this solution reveals an important point: internalizing work ethics is a dialectic, not straightforward, process between individuals and their environment. Suitable circumstances can facilitate individual workers to change their habits, and these individuals in turn can contribute to the transformation of the societal context, whereas it is much more difficult to directly urge individuals to change their habits without any alterations to their environment. These trends are initiated by increasing investments from China in Africa, particularly in manufacturing. If these pioneer investments can effectively build a professional African work force, they will attract even more manufacturing and improve the African environment for industrialization. The convergence of work ethics is not merely beneficial to existing enterprises but may also accelerate a virtuous cycle of wider industrialization across Africa.

Lastly, despite our conviction that the work ethics of industrial capitalism will take over in Africa, as in Asia, America and Europe, we wonder: is this form of work ethics a universal virtue for all societies? With the expansion of industrial capitalism, work ethics based on rigid clock time have become regarded as the most advanced form of ethics, moving ahead of working styles based on traditional time perception. No doubt modern work ethics are fitting for industrial development; however, criticisms of industrial capitalism and developmentalism are worth considering. Are work ethics associated with rigid clock time really of a superior form? To what extent should we encourage the spread of such work ethics? Such discussion is beyond the scope of this paper, but it is important to consider such questions because we may lose many cultural traditions and diversities if we solely focus on the uniform values of industrialization.

\section{Acknowledgements}

This research was funded by an exploratory grant ERG Project 106 and a research grant CEPR PEDL Ref 1386, both from the Center for Economic

81 Interview with Tanzanian workers at T-better Shoe Factory, Dar es Salaam, March 2015.

82 Interview, Sun Linhua. 
Policy Research (CEPR) Private Enterprise Development in Low Income Countries (PEDL). The authors would like to thank two anonymous reviewers for helpful comments.

\title{
Biographical notes
}

TANG Xiaoyang is the deputy director of the Carnegie-Tsinghua Center for Global Policy and an associate professor in the department of international relations at Tsinghua University. His research interests include political philosophy, China's engagement in Africa, and modernization processes in developing countries. He is the author of China-Africa Economic Diplomacy (2014) and has published extensively on Asia-Africa relations. Previously, he worked at the International Food Policy Research Institute in Washington, DC, and as a consultant for the World Bank, the US Agency for International Development, and various research institutes and consulting companies.

Janet EOM is a research associate, and the former research manager, at the China-Africa Research Initiative at the Johns Hopkins School of Advanced International Studies. Her research focuses on comparative studies of US and Chinese development policies towards Africa and the role of technology transfer in African industrialization. Previously, she worked in the Strategy and Policy Unit of the Office of the President in Rwanda and the Carnegie-Tsinghua Center for Global Policy in Beijing on issues of Chinese economic engagement in Africa.

\begin{abstract}
摘要: 在非洲日益增多的中国企业雇用了数以万计的当地劳工。然而, 关于 “勤奋” 的中国人与 “懒情” 的非洲人的刻板成见导致了不少歧视性的管理 行为，同时也影响了对非洲员工的培训和使用。有观点认为中非不同的文 化是两个地区工作伦理差异的主因。但本文对近现代的工作伦理演变过程 进行回顾分析后认为这一观点无法成立。中非之间工作伦理的差异, 更主 要体现在现代标准化时间观念及传统任务型时间观念所导致的不同习惯。 随着中国的市场化改革，“时间就是金钱”的观念作为工业资本主义的基本 原则普遍被中国民众接受，当他们在非洲建厂时，也试图改变非洲员工的 时间观念与工作方式，使其能适应工业化生产的需要。基于坦桑尼亚与埃 塞俄比亚的两个案例对比展示了在不同文化社会环境中, 中国企业如何通 过实践摸索来逐渐培养了非洲员工的现代工作伦理观。
\end{abstract}

关键词: 中非关系; 工作伦理; 时间观念; 雇佣; 培训

\section{References}

Atkins, Keletso. 1988. "'Kafir time': preindustrial temporal concepts and labour discipline in nineteenth-century colonial Natal." The Journal of African History 29(2), 229-244.

Bearak, Barry. 2010. "Zambia balances aid from China and resentment." The New York Times, 20 November, http://www.nytimes.com/2010/11/21/world/africa/21zambia.html.

Brautigam, Deborah. 2009. Dragon's Gift: The Real Story of China in Africa. Oxford: Oxford University Press. 
Brautigam, Deborah, and Xiaoyang Tang. 2014. "'Going global in groups': structural transformation and China's special economic zones overseas." World Development 63, 78-91.

Chen, Xi. 2007. "Zhong-Xi chuantong shijian guan bijiao" (A comparison of Chinese and Western traditional concepts of time). Shidai jiaoyu 9, 54-55.

Cheng, Tao. 2012. "Feizhou de di, shi he ren - huijilu" (Africa's land, objects and people - a memoir). Guojiwang, 29 December, memo.cfisnet.com/2012/1229/1293993.html. Accessed 10 June 2016.

Cohn, Edwin. 1964. "Social and cultural factors affecting the emergence of innovations." In Economic and Social Studies Conference Board (ed.), Social Aspects of Economic Development. Istanbul: Hachette, 105-06.

Cooper, Frederick. 1983. "Urban space, industrial time, and wage labor in Africa." In Frederick Cooper (ed.), Struggle for the City: Migrant Labor, Capital, and the State in Urban Africa Beverly Hills, CA: Sage, 7-50.

Cooper, Frederick. 1992. "Colonizing time: work rhythms and labor conflict in colonial Mombasa." In Nicholas Dirks (ed.), Colonialism and Culture. Ann Arbor, MI: University of Michigan Press, 209-246.

Cooper, Frederick. 1995. "Work, class and empire: an African historian's retrospective on E.P. Thompson." Social History 20(2), 235-241.

Cox, Kevin, David Hemson and Alison Todes. 2004. "Urbanization in South Africa and the changing character of migrant labor." South African Geographical Journal 86(1), 7-16.

Franklin, Benjamin. 1748. Advice to a Young Tradesman. Available at http://founders.archives.gov/ documents/Franklin/01-03-02-0130.

Freund, Bill. 2007. The African City: A History. New York: Cambridge University Press.

Galtung, Marte Kjaer, and Stig Stenslie. 2015. 49 Myths about China. London: Rowman and Littleman.

Gao, Chenglin. 1985. "Shijian jiu shi jinqian xiyi" (An analysis of "time is money"). Caijing kexue 6, 79-80.

Giese, Karsten. 2013. "Same-same but different: Chinese traders' perspectives on African labor." The China Journal 69, 134-153.

Greenhalgh, Susan. 1994. "De-Orientalizing the Chinese family firm.” American Ethnologist 21(4), $746-775$.

Haas, Hein de. 2008. "The myth of invasion: the inconvenient realities of African migration to Europe." Third World Quarterly 29(7), 1305-22.

Hall, Edward T. 1959. The Silent Language. New York: Doubleday.

Hofstede, Geert, and Michael Bond. 1988. "The Confucius connection: from cultural roots to economic growth." Organizational Dynamics 16(4), 5-21.

Huang, Kuang-kuo. 1988. Rujia sixiang yu dongya xiandaihua (Confucianism and East Asian Modernization). Taipei: Zhulin chubanshe.

Kahn, Herman. 1979. World Economic Development: 1979 and Beyond. Boulder, CO: Westview Press.

Landes, David S. 1983. Revolution in Time: Clocks and the Making of the Modern World. Cambridge, MA: Harvard University Press.

Lee, Ching Kwan. 1998. Gender and the South China Miracle: Two Worlds of Factory Women. Berkeley, CA: University of California Press.

Lee, Ching Kwan. 2009. "Raw encounters: Chinese managers, African workers and the politics of casualization in Africa's Chinese enclaves." The China Quarterly 199, 647-666.

Lin, Justin Yifu, and Wang Yan. 2016. Chaoyue fazhan yuanzhu-yige duo ji shijie zhong zhong gou fazhan hezuo xin linian (New Ideas of Development Cooperation in A Multipolar World). Beijing: Beijing daxue chubanshe.

Postone, Moishe. 1996[1993]. Time, Labor, and Social Domination. Cambridge: Cambridge University Press.

Power, Marcus, Giles Mohan and May Tan-Mullins. 2012. China's Resource Diplomacy in Africa: Powering Development? Basingstoke: Palgrave Macmillan. 
Pun, Ngai. 2005. Made in China: Women Factory Workers in a Global Workplace. Durham, NC: Duke University Press.

Sautman, Barry, and Hairong Yan. 2015. "Localizing Chinese enterprises in Africa: from myths to policies." HKUST Institute for Emerging Market Studies, http://iems.ust.hk/wp-content/uploads/ 2015/02/HKUST_IEMS_Thought_Leadership_Brief_Issue5.pdf.

Smith, Arthur. 1894. Chinese Characteristics. New York: Fleming Revell Company.

Tai, Hung-Chao (ed.). 1989. Confucianism and Economic Development: An Oriental Alternative? Washington, DC: Washington Institute Press.

Tang, Xiaoyang, and Irene Yuan Sun. 2016. "Social responsibility or development responsibility?" Cornell International Law Journal 49(1), 69-99.

Thompson, E.P. 1991[1963]. The Making of the English Working Class. London: Penguin Books.

Thompson, E.P. 1967. "Time, work and industrial capitalism." Past and Present 38, 56-97.

Wright, M.W. 2003. "Factory daughters and Chinese modernity: a case from Dongguan." Geoforum 34, 291-301.

Yan, Jun. 2008. "Shijian jiu shi jinqian, xiaolü jiu shi shengming - chongpo sixiang jingu de diyi sheng nahan" (Time is money, efficiency is life: the first cry to break down the thought prison). Chuancheng 2, 1-3.

Yang, Lien-sheng. 1955. "Schedules of work and rest in Imperial China." Harvard Journal of Asiatic Studies 18(3/4), 301-325. doi:10.2307/2718436.

Yeh, Wen-hsin. 2007. Shanghai Splendor: Economic Sentiments and the Making of Modern China, 1843-1949. Berkeley, CA: University of California Press. 